\title{
Structural Design and Material Cutting Using a Laser End Effector on a Robot Arm
}

\author{
Martin Pollák, Jozef Dobránsky \\ Technical University of Košice, Faculty of Manufacturing Technologies with a seat in Prešov, \\ Bayerova 1, 08001 Prešov, Slovak Republic
}

\begin{abstract}
The paper deals with the structural design of a laser end effector for the arm of the ABB IRB 140 robot which makes products by the laser cutting technology involving soft materials, such as e.g. paper, wood and others. A laser with a power of $1 \mathrm{~W}$ was chosen to carry out the cutting. An electrical circuit with a power supply was created for the selected laser; a control method and a structural design of the jig to be attached to the flange of the robot arm were proposed. Subsequently, the robot control program was connected to the control via a computer and the RoboDK simulation software. The paper describes in more detail the creation of the robot control program and the simulation designed in the simulation software environment, as well as the programming of laser control scripts in Python and in the programming environment of Arduino microcontroller.
\end{abstract}

Keywords - Designing, Industrial robot, Laser, Programming, Simulation, RoboDK.

\section{Introduction}

From time immemorial, humanity has been striving to find ways to make work easier. If the arms were insufficient for the activity at hand, it was necessary to make a suitable tool. By improving technological procedures or changing tools, the time required for any given activity has been reduced.

DOI: 10.18421/TEM94-17

https://doi.org/10.18421/TEM94-17

Corresponding author: Martin Pollák, Technical University of Košice, Faculty of Manufacturing Technologies with a seat in Prešov.

Email: martin.pollak@tuke

Received: 02 October 2020.

Revised: 02 November 2020.

Accepted: 07 November 2020.

Published: 27 November 2020.

(cc)BY-NC-ND(C) 2020 Martin Pollák \& Jozef Dobránsky; published by UIKTEN. This work is licensed under the Creative Commons Attribution-NonCommercial-NoDerivs 4.0 License.

The article is published with Open Access at www.temjournal.com
However, the activities performed by humans had their physiological limits, which could be partially expanded through training, but this was not enough. Therefore, it was necessary to replace human labour with a mechanism that could perform the same activity far beyond human predispositions. By making devices capable of operating cyclically, an initial form of automation has essentially come to pass. It offered room for improvement of the production process over time in various directions, and it is no different today. Every day, new ways are sought to increase the efficiency and quality of production. [1], [2], [3]

As it has been mentioned above, suitable equipment can significantly affect the production process. Such a device has to be designed and constructed first [4], [5]. By observing nature and everyday life, it was possible to find inspiration for a number of design options for various manipulators, robotic arms, machine tools, operating machines, etc. [6], [7]. An example is the cooperation of robotics with other branches of technology focused on research in order to achieve desired results, and to ensure the functionality of designs created. [8], [9] These designs are having the form of various methods of material transfer and application, additive component production [10], use of simulation software in project design, as well as the method of controlling components, sensors, readers, lasers, etc. [10], [11]

Zhang X. et al. [12] proposed a 3D printing system using multiple mobile robots to $3 \mathrm{D}$ print a concrete structure. Weiguo $\mathrm{X}$. with Tsinghua University and Shanghai Wisdom Bay Investment Management Company tried to create a bridge made of concrete, using 3D printing via a robotic arm. After testing, they created a bridge design consisting of smaller parts extruded by two robotic arms equipped with $3 \mathrm{D}$ printing systems in 450 hours, thus reducing the necessary costs by up to one third compared to a bridge construction of the same dimensions executed by conventional method. Water-based robotic production has been described by Mogas-Soldevila L. et al. [13] in their paper where they formed hydrogel matrices of chitosan and sodium alginate with other organic aggregates using robotic $3 \mathrm{D}$ 
printing. They used a multi-chamber system connected to a robotic arm for printing. The results achieved represent progress in creation of products from recycled materials. In their study, Moharana B. et al [14] focused on parallel delta robots and compared them with serial robots in terms of use for laser cutting applications. The work of Renate Weissenböck [15], in turn, examines the relationship between digital production and digital design by combining laser cutting techniques and robotic thermoforming of acrylic glass, resulting in the creation of new, three-dimensional spatial objects of desired geometry.

\section{Laser Cutting and Engraving}

In the process of laser cutting, material is separated by evaporation at high temperatures. The laser converts electrical energy into light, which radiates directly into the material, which is then heated. Laser is a universal tool for cutting material. Laser cutting can be done in several ways:

- by melting the material and then blowing the material away;

- by sublimation cutting, where the material is heated to the evaporation temperature;

- by cutting using active gas, which accelerates the heating of the material and thus the cutting process.

Industrial laser applications include cutting, measuring, engraving, 3D printing, polishing, cleaning, welding and drilling. It is also used in other industries, such as medicine, the military, chemical industry, and electrical engineering. The Nd: YAG laser is most often used for cutting metals. The $\mathrm{CO} 2$ laser has a broader application, as it enables to cut other materials such as plastic, leather and textiles. [16]

Before choosing the laser, a thought has to be given to its intended application. This requirement also follows from knowing the reflectivity of the material for the selection of a particular laser types and the radiation of which the material is to absorb. Metals tend to have high reflectivity. Also, in addition to the material type, the colour of the material also affects the reflectivity. For cutting glossy surfaces, it is ideal to coat the surface of the material with a matte paint that reduces reflectivity. The material changes its reflectivity properties even with a change in temperature (as the temperature increases, the reflectivity decreases). [17]

\section{Laser Selection and Connection Design}

A $1 \mathrm{~W}$ blue light semiconductor laser with an open head was used to make the laser end effector. A power supply with a 7,5 V/1,5 A output was selected to feed the device. A thermal paste, which was applied between the heatsink and the integrated circuit, was used as the thermal conductor. The heatsink incorporated in the circuit is used to cool the transistor. A $1 \mathrm{~W}$ laser produces more thermal energy; therefore, a diagram was designed so that the laser does not emit light continuously. Before the final connection of the semiconductor diode, a test circuit, by means of which the magnitude of the electric current to pass through the laser diode was set, was made. The required resistance was set using a multi-turn trimmer. The resulting power at $1 \mathrm{~A}$ is 1 W.

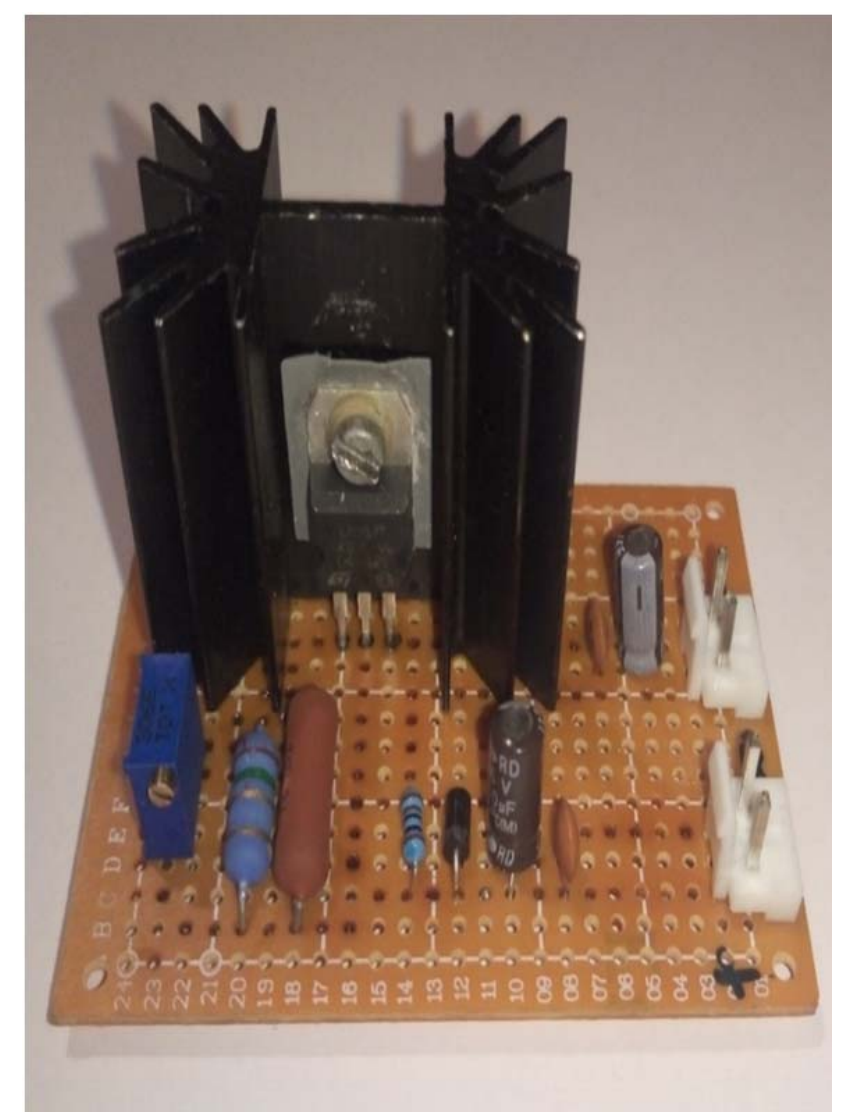

Figure 1. Electrical circuit for 1 W laser

\subsection{Design of a Jig for Attaching a Laser end Effector to a Robot Flange}

The main part of the body of the jig was made using 3D printing technology, to which a fan was attached with 4 screws to supply air between the fins of the heatsink and also as a source of air supply to the material cutting spot. Laser housing, covered with thermal paste, was inserted into an aluminium heatsink block with fins, fastened with two screws to prevent its movement. The laser housing itself consists of built-in optics and a laser diode. The 
heatsink and the housing assembly were then fastened to the main part of the jig body with 4 screws. The power cords were inserted through an opening made in the back of the jig body. Thus, created assembly of the laser end effector was subsequently attached to the flange of the robot arm.

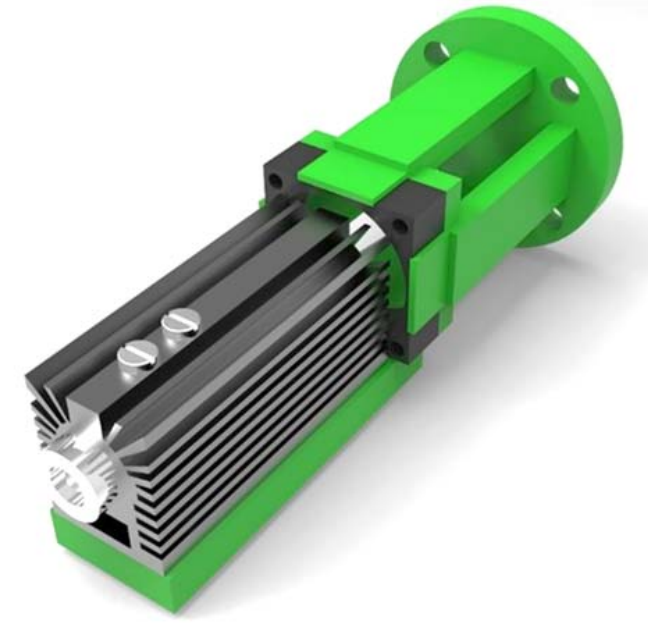

Figure 2. Assembled head jig with the laser

\subsection{Design of the Laser Control Method}

In order to prevent continuous light emission by the laser, it was necessary to design a method of controlling it. Deployed to control the laser was an Arduino microcontroller in combination with a relay and the Python programming language. This programming language was chosen due to the fact that RoboDK (simulation software) manufacturer supports Python. The first control program was programmed as a script to send an instruction to the Arduino microcontroller in the form of logic 1 or logic 0 via the USB port. The second program was written in the Arduino board environment. Upon receiving an instruction from the USB bus, this code activated the relay. However, a problem arose during the simulation. Having completed the step (script), the RoboDK simulation program returned the value to match the original state. This issue has been resolved by rewriting the Arduino code. The code was modified so that after receiving the value from the USB bus, the program remembered the value it received until the next value was received. The Python code has also been modified and split into two separate scripts to send a value of 0 and a value of 1 .

\section{Simulation Design and Creation of a Robot Control Program}

A simulation model was created in the RoboDK program environment to carry out the cutting with the laser end effector. The assembly made of the jig with the laser was placed on the flange of the arm of the ABB IRB 140 robot in the working space created.
Subsequently, the coordinates and reference points of the objects were edited for the correct placement of the objects and the selection of the optimal distance of the effector from the object representing the geometry of the object to be cut.

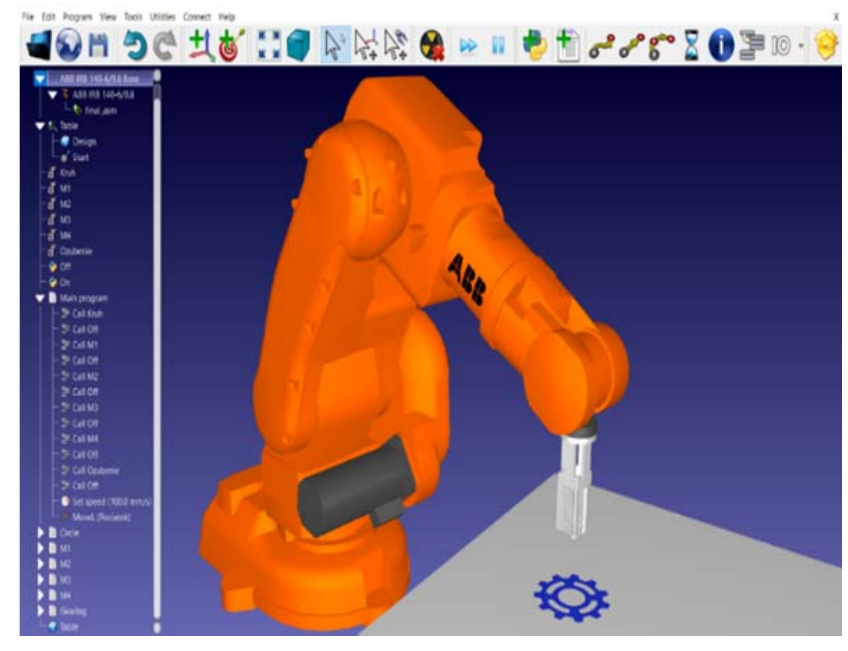

Figure 3. Simulation model designed in RoboDK software environment

The correct definition of the working space was followed by the creation of the main program and the relevant subprograms, requisite for defining the cutting trajectory of the laser end effector located on the flange of the robot arm.

Python scripts have been created to control the laser on and off. The created script was then added to the RoboDK software using the "Add Python program" function. After connecting the Arduino microcontroller, it was necessary to overwrite the port values in the script, depending on the position to which the microcontroller is assigned by the computer. The task of the script is to send a signal value of 0 , which ensures that the laser is switched off, or a value of 1 to switch the laser on.

After this step, the main program was created using "Adds a new program linked to the selected robot". The main program referred to the created subroutines. A call to the Python script was added to the subroutines, with the instruction to turn off the laser (signal value 0). Restarting the laser was initiated by a function directly in the subroutine. Such solution was chosen due to the fact that after completing the subroutine, the laser has to get into the position for starting the next subroutine. During this move, the laser has to be off, and only after moving to the new start position the script, which turns it on, is called onto. The last step was to return the robot arm to the starting position. The whole main program was simulated and then a code was generated, which can be uploaded into the robot control unit using a USB flash drive. In this case, the more ideal solution was to connect the robot to the computer using a LAN cable, and thus control the 
robot directly with the simulation program designed. The advantage of this connection is also the possibility of controlling the laser directly during the simulation from the control computer's USB port.

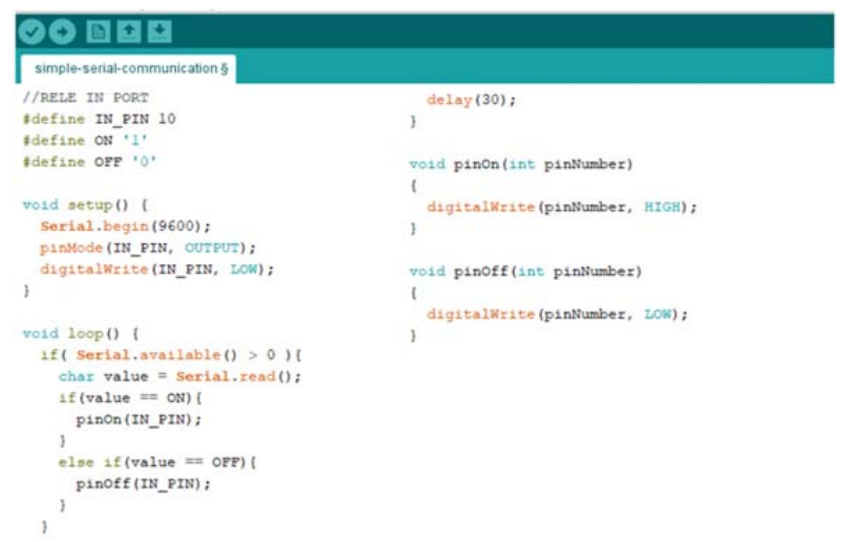

Figure 4. The program created for controlling the Arduino microcontroller

The control program for Arduino was created directly in the Arduino environment. The task of this program is to receive a signal from the USB port on condition of remembering the last received value of the state, until the time a new value of the state is obtained.

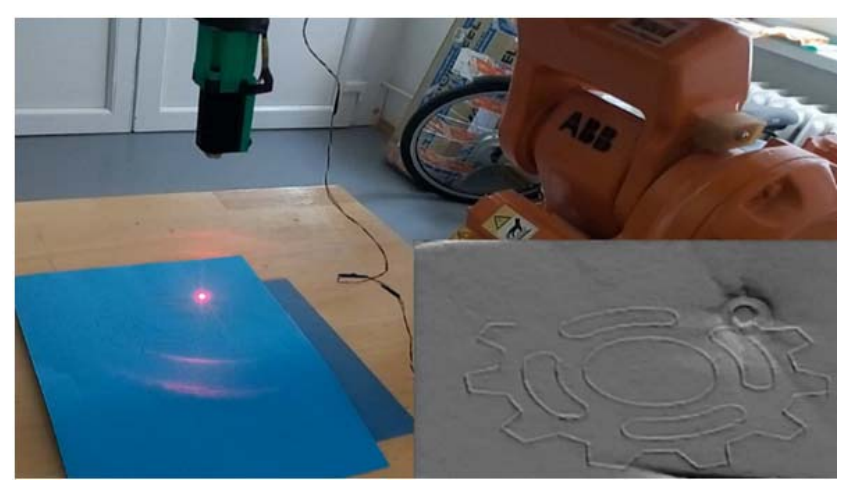

Figure 5. Carrying out the cutting with designed laser end effector

In cutting, a problem may occur due to uneven surface. For this reason, it is ideal to carry out the cutting on a flat surface, as it is not necessary to adjust the laser focus. Alternatively, if the surface curvature model is known, the software allows defining the robot's motion when creating the program, so that the beam incident on the surface is always at the focal point. Fig. 6 is an illustration of a cut-out paper object. Due to the good absorption of the red spectrum, it is advisable to choose a material from which the laser beam will not be reflected, thus ensuring the desired cut through the material.

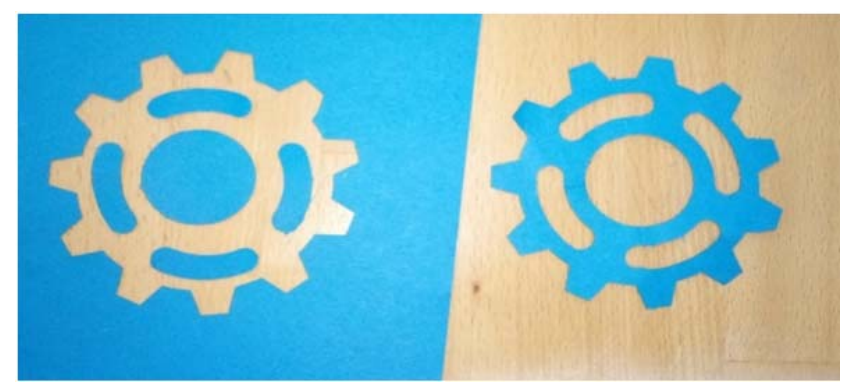

Figure 6. Example of a cutout object

By using the robot arm for laser cutting, it is possible to cut surfaces of various shapes in threedimensional space. However, creating a program for such curved surfaces is more difficult. It is very important to keep the beam focused at the required distance at all times. Approximation to the distance required can be resolved by fixating the optics and constantly maintaining the distance from the machined surface at a firmly defined distance. Another option is to control the focus using an additional stepper motor on the optics. In case of a known distance of the laser from the surface of the material at different steps of the motor, the cutting could take place at different levels of approximation.

\section{Conclusion}

The aim of the paper is to draw attention to the possibility of using laser cutting technology by deploying a robot arm. A semiconductor diode (laser) was used for cutting, for which an electrical circuit was assembled. The setting of the required current and voltage for the laser with a power of $1 \mathrm{~W}$ was described. A heatsink and a thermal paste were used to cool the regulator. The power supply was ensured from a $7.5 \mathrm{~V}$ source. All the necessary components of the assembly were modelled, and the movements of the laser effector were created using the RoboDK program. These were then simulated, and a robot control program was generated. Using the Arduino microcontroller and Python, scripts were created to control the laser's switching on and off. These signals were sent via the computer's USB bus. The simulation of the robot's movement occurred via a LAN connection to ensure direct control from the software environment. At the same time, instructions for turning the laser on and off were sent via the computer's USB port. The result of the design regarding the cutting solution employing a laser effector mounted on the flange of the robot arm is an indication of the possibilities of interconnecting several technologies and verifying their suitability for cutting objects. 


\section{Acknowledgements}

The authors thank the Ministry of education of Slovak Republic for supporting this research by the grant VEGA no. 1/0026/19.

\section{References}

[1]. Poor, P., \& Basl, J. (2018). Czech Republic and Processes of Industry 4.0 Implementation. Annals of DAAAM \& Proceedings, 29.

[2]. Panda, A., Nahornyi, V., Pandová, I., Harničárová, M., Kušnerová, M., Valíček, J., \& Kmec, J. (2019). Development of the method for predicting the resource of mechanical systems. The International Journal of Advanced Manufacturing Technology, 105(1-4), 1563-1571.

[3]. Iglesias, I., Sebastián, M. A., \& Ares, J. E. (2015). Overview of the state of robotic machining: Current situation and future potential. Procedia engineering, 132, 911-917.

[4]. Novak-Marcincin, J., Janak, M., Barna, J., Torok, J., Novakova-Marcincinova, L., \& Fecova, V. (2012). Verification of a program for the control of a robotic workcell with the use of AR. International Journal of Advanced Robotic Systems, 9(2), 54.

[5]. Straka, L., \& Dittrich, G. (2020). Design of Manufacturing Process of Mould for Die Casting by EDM Technology with the Computer Aided. International Journal of Engineering and Management Sciences, 5(2), 57-63.

[6]. Uhlmann, E., Heitmüller, F., Manthei, M., \& Reinkober, S. (2013). Applicability of industrial robots for machining and repair processes. Procedia Cirp, 11, 234-238.

[7]. Poor, P., Basl, J., \& Ženíšek, D. (2020). Assessing the predictive maintenance readiness of enterprises in West Bohemian region. Procedia Manufacturing, 42, 422-428.
[8]. Zaborowski, T., Panda, A., Androvic, L., \& Onofrejova, D. (2019). Robots and cobots, main differences. Studia i Materiały, 39(6), 4-8.

[9]. Broum, T., \& Šimon, M. (2020). Safety requirements related to collaborative robots in the Czech Republic. In MM Science Journal, 1, 3852-3856.

[10]. Torok, J. O. Z. E. F., Kocisko, M. A. R. E. K., Teliskova, M. O. N. I. K. A., Petrus, J. A. R. O. S. L. A. V., \& Paulisin, D. U. S. A. N. (2018). Quality of $3 \mathrm{D}$ printed surface based on selected post processor. MM Science Journal, 6, 2346-2349.

[11]. Stejskal, T., Dovica, M., Svetlik, J., \& Demec, P. (2019). Experimental assessment of the static stiffness of machine parts and structures by changing the magnitude of the hysteresis as a function of loading. Open Engineering, 9(1), 655-659.

[12]. Zhang, X., Li, M., Lim, J. H., Weng, Y., Tay, Y. W. D., Pham, H., \& Pham, Q. C. (2018). Large-scale 3D printing by a team of mobile robots. Automation in Construction, 95, 98-106.

[13]. Mogas-Soldevila, L., Duro-Royo, J., \& Oxman, N. (2014). Water-based robotic fabrication: large-scale additive manufacturing of functionally graded hydrogel composites via multichamber extrusion. $3 D$ Printing and Additive Manufacturing, 1(3), 141-151.

[14]. Moharana, B., Gupta, R., \& Kushwaha, B. K. (2014). Optimization and design of a laser-cutting machine using delta robot. arXiv preprint arXiv:1404.6029.

[15]. Weissenböck, R. (2015). Robotic DesignFabrication-Exploring Robotic Fabrication as a Dynamic Design Process. In Real Time-Proceedings of the 33rd eCAADe Conference-Volume 2 (pp. 309318).

[16]. Straka, L', \& Hašová, S. (2016). Assessing the influence of technological parameters on the surface quality of steel MS1 after WEDM.MM Science Journal, 11, 1194-1200.

[17]. Legutko, S. (2009). Development trends in machines operation maintenance. Eksploatacja i NiezawodnoscMaintenance and Reliability, (2), 8-16. 